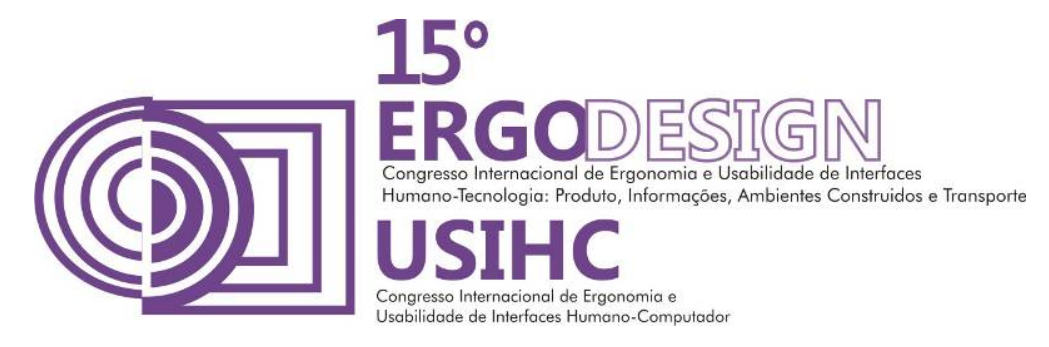

\title{
A QUALIDADE AMBIENTAL NO INTERIOR DO EDIFÍCIO DA FACULDADE DE ARQUITETURA DA UFJF
}

\author{
BRAIDA, Frederico (1); \\ RAPOSO, Myrtes (2); \\ CostA, Layse (3); \\ NETTO, Luyla (4).
}

(1) Universidade de Juiz de Fora, Faculdade de Arquitetura e Urbanismo, Departamento de Projeto, Representação e Tecnologia. Mestre, Doutor e Pós-Doutor em Design (PUC-Rio).

e-mail: frederico.braida@ufjf.edu.br

(2) Universidade Federal de Juiz de Fora, Instituto de Artes e Design. Especialista em Ergonomia (UFJF). Mestre em Design (PUC-Rio).

e-mail:myrtes.raposo@ufjf.edu.br

(3) Universidade Federal de Juiz de Fora, Bolsista de Iniciação Científica do Grupo LEAUD.

e-mail: layse souzacostame@hotmail.com

(4) (3) Universidade Federal de Juiz de Fora, Bolsista de Iniciação Científica do Grupo LEAUD.

e-mail:luyla.ifet@hotmail.com

\begin{abstract}
RESUMO
Este artigo objetiva apresentar os resultados de uma pesquisa que teve por finalidade o levantamento sistematizado das diversas barreiras existentes no espaço físico do edifício da Faculdade de Arquitetura e Urbanismo da Universidade Federal de Juiz de Fora à luz das interfaces entre os campos da Arquitetura, Design e Ergonomia do Ambiente Construído. Na pesquisa foi utilizada a metodologia da Intervenção Ergonomizadora proposta por Moraes e Mont'Alvão (2007), contemplando-se as etapas de Apreciação e Diagnose, culminando na apresentação de um quadro de sugestões de melhorias direcionado à equipe responsável pelo projeto de reforma do edifício que está em andamento.
\end{abstract}

\section{ABSTRACT}

This article presents the results of a research that aimed to the systematic survey of all existing barriers in the physical space of the building of the Faculty of Architecture and Urbanism at the Federal University of Juiz de Fora in the light of the interfaces between the fields of Architecture, Design and Ergonomics of the Built Environment. In the survey we used the the methodology proposed by Moraes and Mont'Alvão 


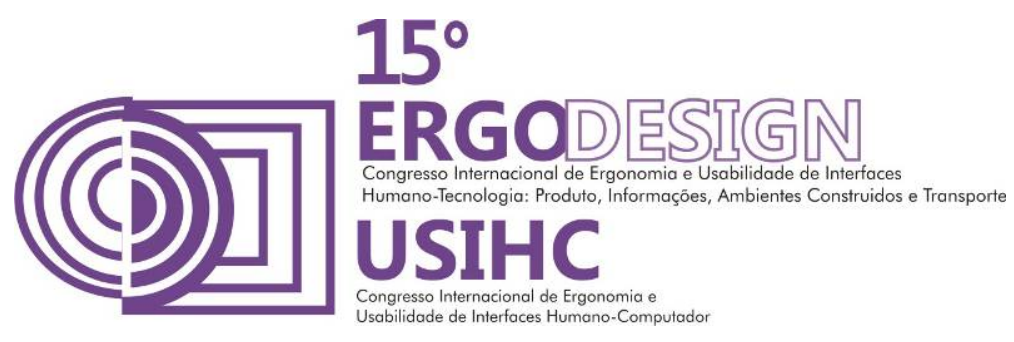

(2007), focused on Assessment and Diagnosis steps, culminating with a presentation of an improvement suggestions board to the team responsible for the renovation building design that is in progress.

\section{INTRODUÇÃO}

O presente artigo é fruto de uma investigação do Grupo de Pesquisa das Linguagens e Expressões da Arquitetura, Urbanismo de Design (LEAUD), vinculado à Faculdade de Arquitetura e Urbanismo da Universidade Federal de Juiz de Fora (UFJF), a qual teve por finalidade abordar o tema da qualidade ambiental no edifício principal da referida Faculdade, contemplando-se os conceitos de Desenho Universal, Inclusão Social e Acessibilidade para a proposição de melhorias na acessibilidade do prédio, à luz das interfaces entre os campos da Arquitetura e Urbanismo, Design e Ergonomia do Ambiente Construído.

Especificamente, este artigo tem por objetivo apresentar os resultados da pesquisa, demonstrando as diversas barreiras arquitetônicas existentes e identificadas no espaço físico do edifício da Faculdade de Arquitetura da UFJF, as quais acabam por restringir a acessibilidade e a mobilidade a determinados setores da edificação ou, ainda, o que é pior, por segregar o público que se encontra apto a acessar tal espaço que, por pressuposto de um edifício público, deveria estar ao alcance de todos.

Deve-se destacar que a pesquisa seguiu na esteira das recentes preocupações da UFJF, bem como de outras Instituições, com o tema da acessibilidade e mobilidade urbana. Durante as últimas décadas, sobretudo a partir dos anos de 1980, o tema da mobilidade urbana tem atraído a atenção dos pesquisadores e profissionais de diversas áreas do conhecimento humano, dentre as quais se destacam a Arquitetura, o Urbanismo, o Design, a Ergonomia e as Engenharias. Conceitos como Desenho Universal, Inclusão Social e Acessibilidade tornaram-se pauta de reflexões que visam à melhoria da qualidade do ambiente em que os homens circulam (MORAES; MONT'ALVÃO, 2007).

Sendo assim, os conceitos de Desenho Universal e de Acessibilidade mostram-se fundamentais para ampliação da compreensão da inclusão social pelo ambiente construído. O conceito de Desenho Universal visa à concepção de objetos, equipamentos, ambientes e meios de comunicação destinados a ser utilizados por todos, sem necessidade de adaptação, beneficiando pessoas de todas as idades, estatura e capacidades. Seu objetivo é simplificar a vida de todos, a fim de possibilitar a integração numa sociedade inclusiva. Já a Acessibilidade, segundo a NBR 9050/2004 é a "possibilidade e condição de alcance, percepção e entendimento para a utilização com segurança e autonomia de edificações, espaço, mobiliário, equipamento urbano e elementos" (ABNT, 2004). Logo, a promoção da acessibilidade requer a identificação e eliminação dos diversos tipos de barreiras que impedem os seres humanos de realizarem atividades e exercerem funções na sociedade em que vivem, em condições similares aos demais indivíduos.

É nesse contexto que o tema da acessibilidade aos edifícios públicos tem merecido atenção. Em busca de uma sociedade mais justa e inclusiva (CORRÊA, 2008), a inserção de pessoas com deficiências - sejam elas temporárias ou permanentes - no ambiente construído tornouse uma necessidade urgente, seja por força de lei ou por reflexo de uma consciência coletiva inclusiva. Pode-se citar, como exemplo, o fato de ter tornado obrigatório no Brasil, em 2000, pela Lei 10.098, o cumprimento dos critérios básicos para a acessibilidade de pessoas com 


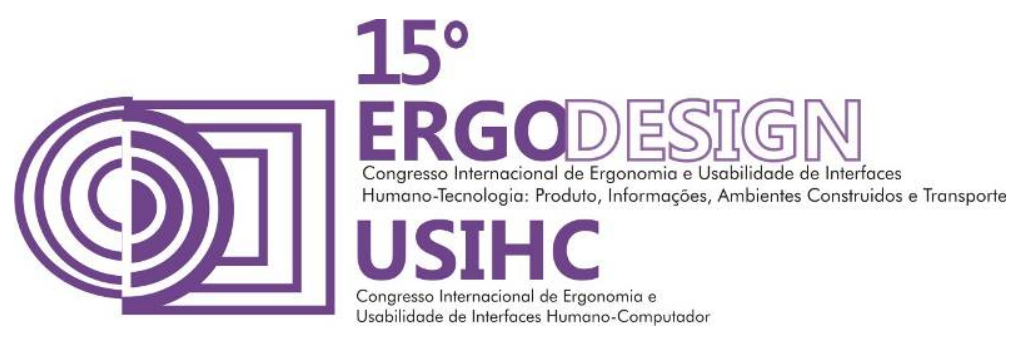

deficiência ou com mobilidade reduzida em todas as vias e espaços públicos e de uso coletivo (MEIRA; ARAÚJO, 2013).

De acordo com a NBR 9050, são considerados edifícios de uso público "espaços, salas ou elementos externos que são disponibilizados para o publico em geral, o uso público pode ocorrer em edificações ou equipamento de propriedade pública ou privada" (ABNT, 2004). Ressalta-se, pois, que o acesso a tais lugares é um direito de qualquer cidadão. Então, deve-se garantir que qualquer pessoa, independente de suas capacidades físicas e sensoriais, possa acessar as áreas dos edifícios públicos, o que inclui principalmente as instalações públicas universitárias, visto que estas desempenham na sociedade o importante papel de produtor e difusor de cultura e conhecimento. Além disso, os espaços das instituições públicas de ensino são reconhecidos como paradigma de democracia, uma vez que recebem uma grande diversidade de usuários, seja em função de sua procedência, idade, classe social, cultura, ou mesmo aptidões físicas, sensoriais e cognitivas (DUARTE; COHEN, 2004).

Destaca-se, ainda, que o espaço construído exerce um papel fundamental na superação das desigualdades físicas e sociais. Contudo, de acordo com Duarte e Cohen (2004), a maioria destes estabelecimentos não está preparada para acolher pessoas com deficiência porque apresentam inúmeras barreiras à acessibilidade. É, justamente, a partir de tal constatação que a investigação e a proposição de eliminação de barreiras físicas espaciais no prédio da Faculdade de Arquitetura e Urbanismo da UFJF justifica-se como relevante e emergiu de uma demanda concreta, uma vez que o edifício sofrerá reformas, para as quais já está em curso um novo projeto. Assim, espera-se que os resultados da pesquisa, aqui relatados, possam contribuir, no âmbito específico, para uma melhoria da qualidade ambiental no referido edifício e, em uma escala mais ampla, para a motivação de eliminações de barreiras comumente encontradas em edifícios universitários.

Por fim, à guisa de introdução, cumpre mencionar que a incorporação de soluções de acessibilidade em um edifício de uma Faculdade de Arquitetura e Urbanismo, bem como de outros cursos de intervêm diretamente no ambiente construído (como Design e Engenharia), tem um papel pedagógico, uma vez que inserir os estudantes do curso em um ambiente em que os temas da inclusão social, eliminação de barreiras, acessibilidade espacial e mobilidade urbana não sejam meros discursos ou frutos apenas de elucubrações teóricas apresenta-se como fundamental e urgente para que, partindo-se de uma premissa de que "a educação vem de casa", os alunos possam seguir o exemplo do local onde estudaram e incorporar tais conceitos, de forma pragmática, em seus projetos profissionais.

\section{CARACTERIZAÇÃO DO OBJETO DE ESTUDO}

O edifício que atualmente abriga a Faculdade de Arquitetura e Urbanismo (popularmente como "Galpão da Arquitetura"), objeto empírico da pesquisa levada a cabo e aqui relatada, está localizado no campus da Universidade Federal de Juiz de Fora, Rua José Lourenço Kelmer, sem número, no bairro São Pedro, na cidade de Juiz de Fora, região da Zona da Mata mineira. Ele faz parte do complexo de edifícios que compõem a Plataforma do Setor de Tecnologia da UFJF.

Pode-se dizer que a história desse edifício remonta à criação do campus em que está inserido, em 1965. Construído com uma tipologia de galpão, com acabamento semelhante ao dos 


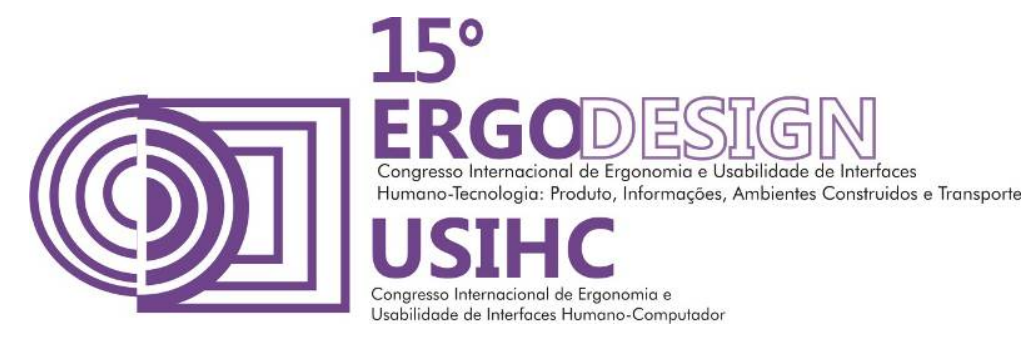

demais edifícios do campus dessa mesma época (concreto e tijolos aparentes), ao longo dos anos a edificação já sofreu algumas reformas. Em 1992, com a criação do Curso de Arquitetura e Urbanismo da Faculdade de Engenharia da UFJF, o Galpão 4 da faculdade foi cedido para a estruturação deste novo curso. Com a necessidade de adequar-se à Resolução $n^{0} 6$ de 2 de fevereiro de 2006 do Ministério da Educação (MEC), foi criada uma comissão para discutir possíveis estratégias de ocupação do espaço físico para a reforma que ocorreu em 2008.

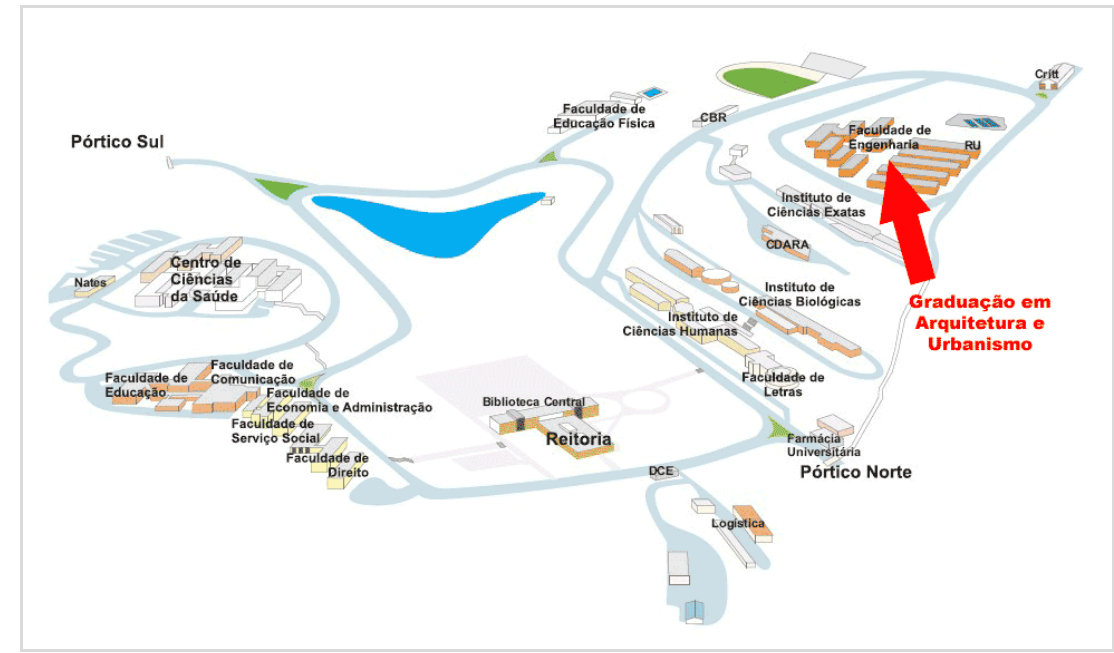

Figura 1- Localização do Galpão da Faculdade de Arquitetura e Urbanismo (UFJF). Disponível em: <http://www.ufjf.br/poseconomia/outros/localizacao/>. Acesso em: 4 jan. 2015.

Nos dias de hoje, o edifício apresenta as seguintes características, conforme as plantas-baixas apresentadas nas figuras 2 e 3: são dois pavimentos, nos quais se distribuem 15 salas de aula e/ou laboratórios e 11 gabinetes de professores, 1 sanitário para deficiente físico, 2 sanitários femininos e 2 sanitários masculinos para alunos e 1 sanitário feminino e 1 masculino para professores, 1 vestiário para funcionários, 1 deposito de material de limpeza, 1 sala de recepção e amplos saguões em ambos os pavimentos. 

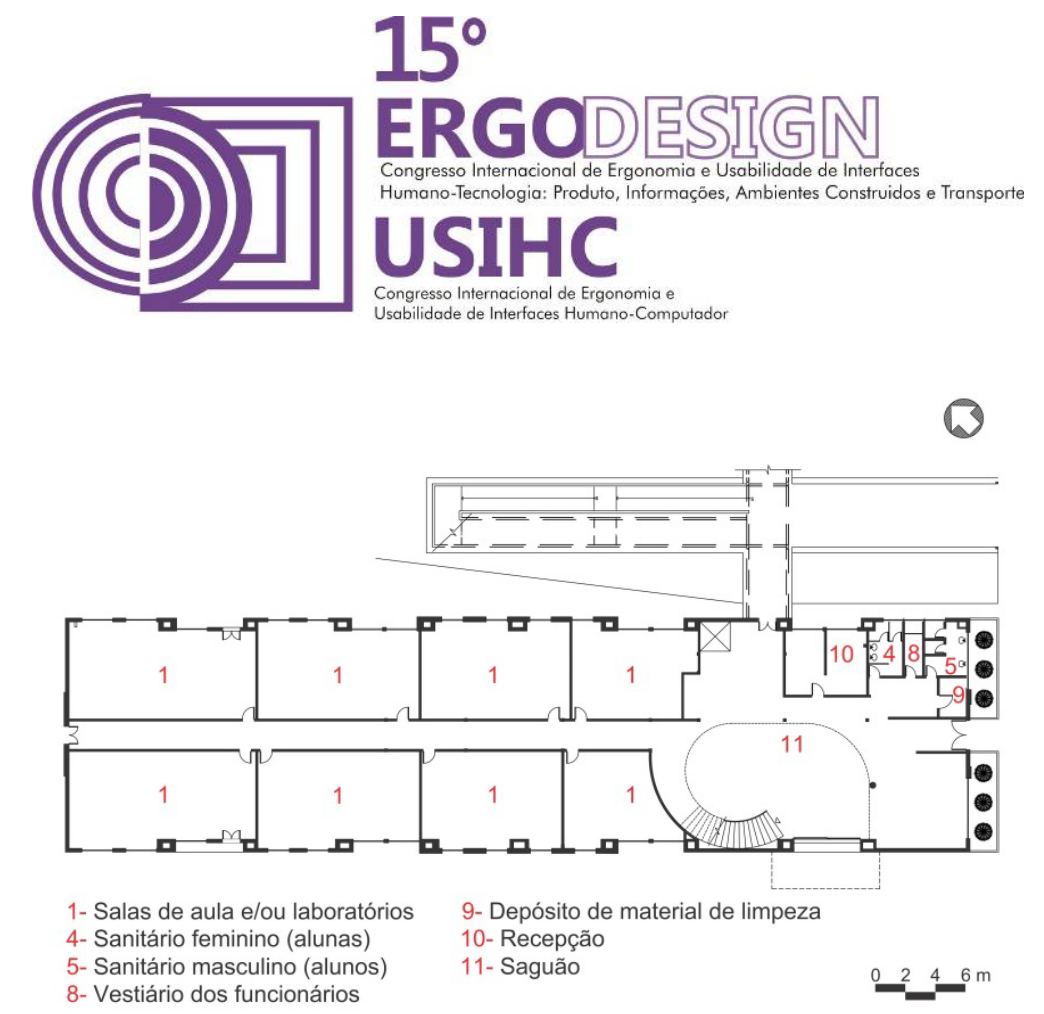

Figura 2 - Planta baixa do $1^{\circ}$ pavimento do Edifício da Faculdade de Arquitetura da UFJF. Fonte: Dos autores, 2014.

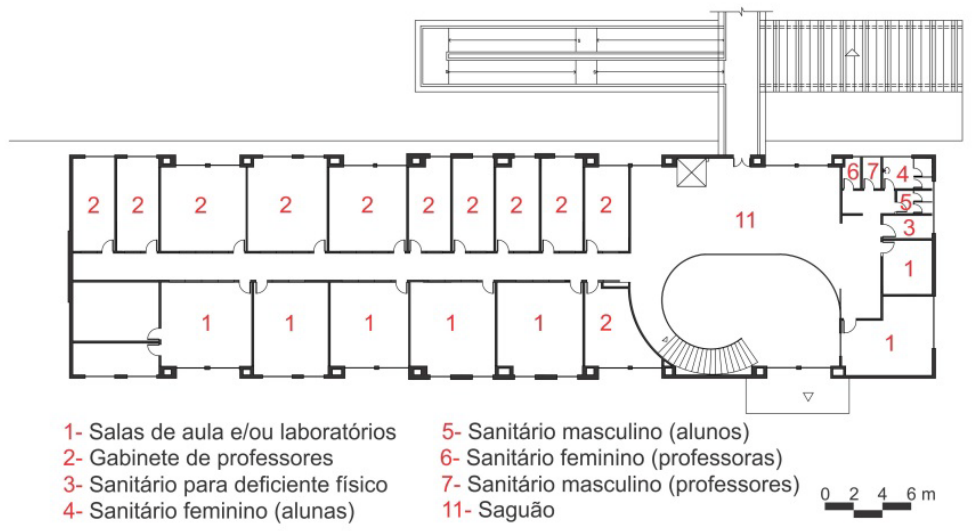

Figura 3 - Planta baixa do $2^{\circ}$ pavimento do Edifício da Faculdade de Arquitetura da UFJF. Fonte: Dos autores, 2014.

O principal acesso ao pavimento superior se dá por meio de uma escada monumental, localizada no amplo saguão do edifício (Figura 4), embora haja uma rampa com inclinação de oito por cento na parte externa da edificação (Figura 5). 


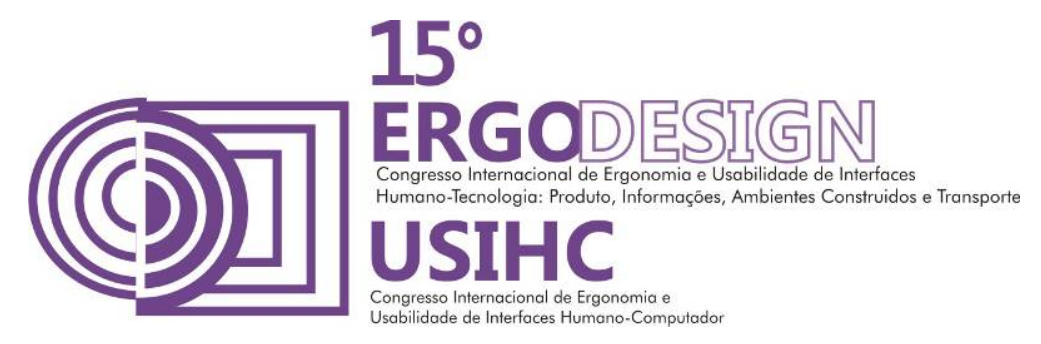

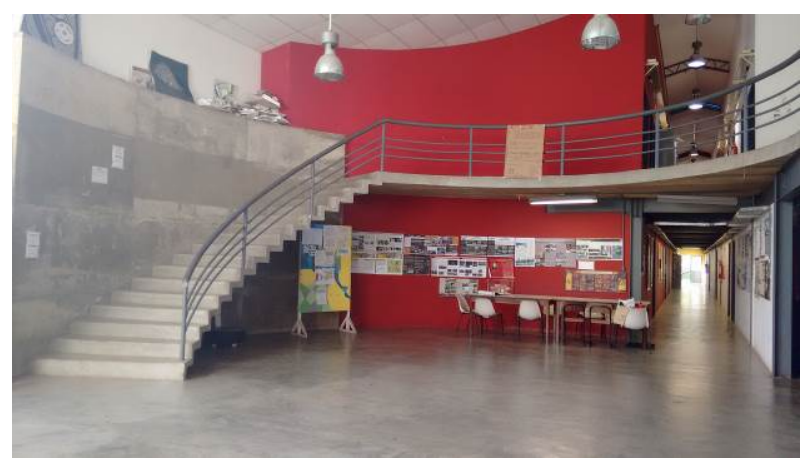

Figura 4 - Escada. Fonte: Dos autores, 2014.

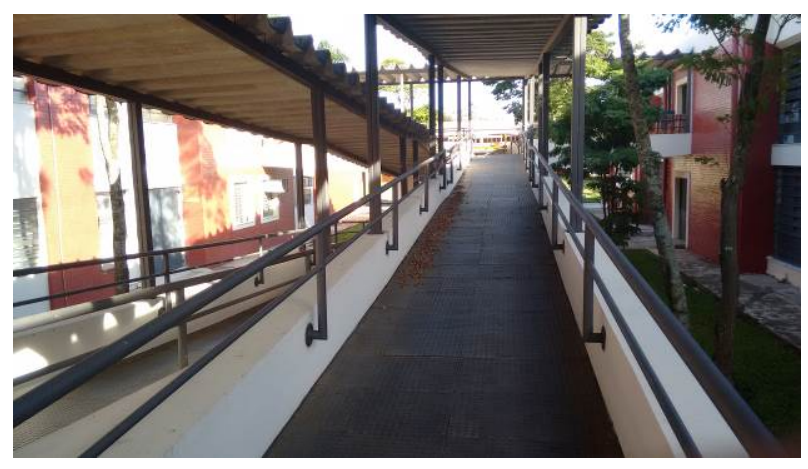

Figura 5 - Rampa. Fonte: Dos autores, 2014.

No ano de 2014, com a criação da Faculdade de Arquitetura e Urbanismo, desvinculando-se da Faculdade de Engenharia, fez-se necessário uma nova reforma no galpão, a fim de adequar-se às novas demandas espaciais. O projeto desta reforma ainda está sendo discutido. Nesse sentido, a pesquisa aqui relatada mostra-se relevante para a identificação das barreiras físicas existentes e proposição de soluções que possam ser incorporadas ao novo projeto.

\section{ASPECTOS METODOLOGICOS DA PESQUISA}

$\mathrm{Na}$ pesquisa aqui relatada foi utilizada a metodologia da Intervenção Ergonomizadora proposta por Moraes e Mont'Alvão (2007). As etapas contempladas até o presente momento foram as de Apreciação e Diagnose, culminando na apresentação de um quadro de sugestões de melhoria para a equipe responsável pelo projeto de reforma do edifício.

Para a coleta de dados, foram realizadas observações assistemáticas e sistematizadas in loco, conforme será descrito a seguir. Os registros se deram por meio de fotografias, anotações em plantas baixas e diários de pesquisa. Tais observações foram, ainda, direcionadas pela aplicação de planilhas de avaliação.

Cabe, também, mencionar que a coleta de dados complementou-se com a realização de uma imersão (vivência) por parte dos pesquisadores, de tal modo a aproximá-los da realidade das pessoas com deficiência e mobilidade reduzida.

A análise dos dados levantados se deu por meio da comparação com as sugestões da Planilha de Avaliação referenciada na NBR 9050 e decretos pertinentes. Foi a partir da sistematização das análises que foram criados os quadros com as recomendações apresentadas na última seção deste artigo.

\subsection{Levantamento e Observações in Loco}

Configurou-se como uma fase eminentemente de coleta de dados, ou seja, de levantamentos e de observação realizados in loco. Para esta fase foram empregados os recursos de setorização da edificação e de planilhas elaboradas em conformidade com a legislação vigente, onde foram registrados os dados coletados. Também se criou um banco de dados iconográficos, construído a partir do levantamento fotográfico. 


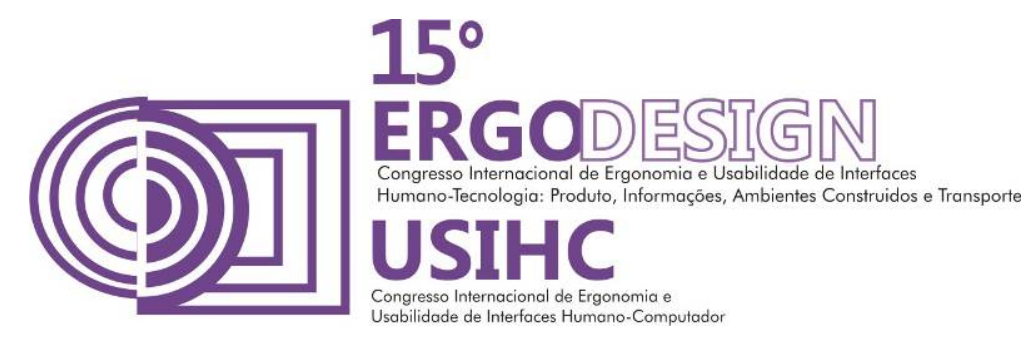

Nesta fase, utilizaram-se Planilhas de Avaliação desenvolvidas no Programa de Acessibilidade às Pessoas com Deficiência ou Mobilidade Reduzida nas Edificações de Uso Público do Ministério Público de Santa Catarina. Ressalta-se que tal planilha foi adequada ao edifício analisado, o que resultou em uma derivação da original, apresentada na figura 6 . Nestas planilhas são considerados critérios referentes às normas NBR 9050 - Acessibilidade a edificações, mobiliário, espaços e equipamentos urbanos (ABNT, 2004), NBR 9077 - Saídas de emergência em edifícios (ABNT, 2001) e NBR 13994 - Elevadores de passageiros - Elevadores para transporte de pessoa portadora de deficiência (ABNT, 2000).

Vale ressaltar que a planilha utilizada é subdividida em: (a) identificação (N.); (b) legislação (Lei / Artigo); (c) componente de acessibilidade (C), (d) item a conferir, (e) resposta (sim / não / não se aplica ou inexistente), (f) observações.

\begin{tabular}{|c|c|c|c|c|c|c|c|c|}
\hline \multicolumn{9}{|c|}{ PLANILHA 1 - Saguão, recepção, administração } \\
\hline \multirow{2}{*}{ N. } & \multicolumn{2}{|c|}{ Legislação } & \multirow{2}{*}{ C } & \multirow{2}{*}{ Itens a conferir } & \multicolumn{3}{|c|}{ Resposta } & \multirow{2}{*}{ Observação } \\
\hline & Lei/NBR & Artigo & & & Sim & Não & N.A/I & \\
\hline \multicolumn{9}{|c|}{$\begin{array}{c}\text { Mobiliario de atendimento e } \\
\text { espera }\end{array}$} \\
\hline 1.1 & - & - & 2 & $\begin{array}{l}\text { O balcão de atendimento } \\
\text { recepção pode ser identificado } \\
\text { visualmente ou por informação } \\
\text { adicional (placa) desde a porta } \\
\text { de acesso ao edifício? }\end{array}$ & & $\mathrm{X}$ & & \\
\hline
\end{tabular}

Figura 6 - Exemplo de parte da planilha aplicada durante a observação e coleta de dados. Fonte: Dos autores, 2014. Adaptado de Dischinger et al. (2012).

Como forma de otimizar o levantamento e torná-lo mais compreensível, além de sistematizar os dados, optou-se pela setorização do prédio. Para cada um dos cinco setores foi atribuída uma cor, conforme figura 7.
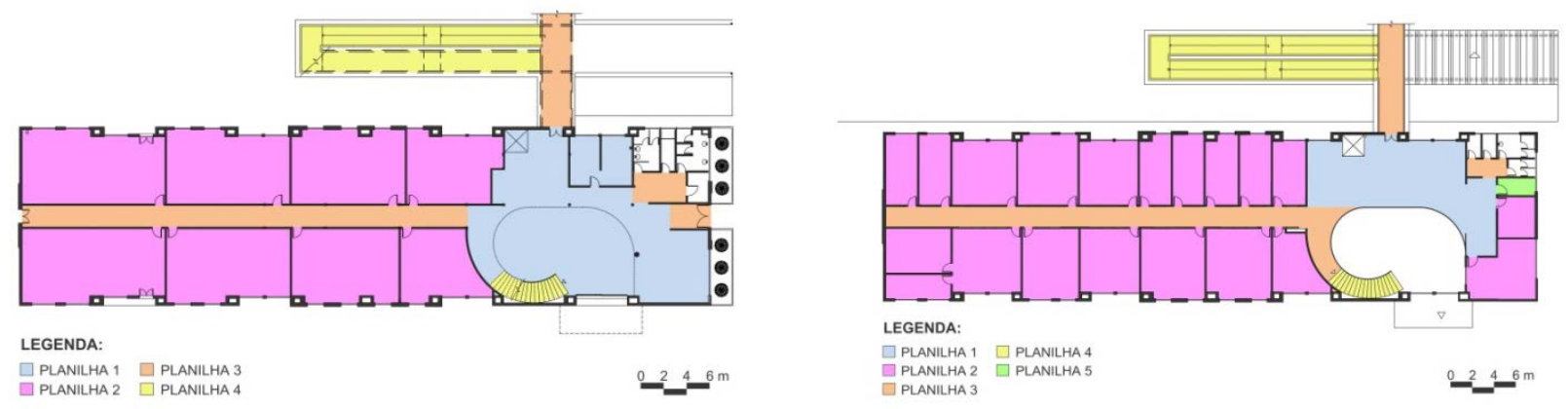

Figura 7 - Setorização dos pavimentos para fins de elaboração das Planilhas de Avaliação. Fonte: Dos autores, 2014.

Os setores foram divididos conforme os usos dos ambientes abaixo: 


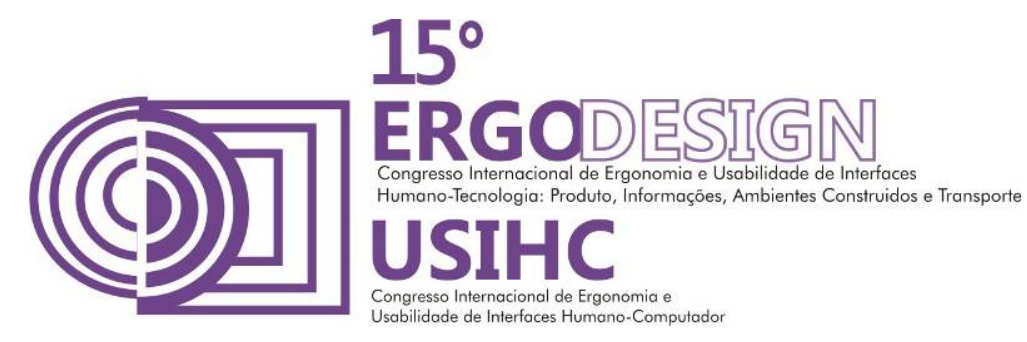

Planilha 1 (cor azul) - Saguão, recepção, administração: compreendem o conjunto de áreas adjacentes às entradas, incluindo a área de atendimento ou recepção, área para espera, os corredores e o seu mobiliário.

Planilha 2 (cor magenta) - Circulação Horizontal: compreendem o conjunto de corredores e saguões dos setores que interligam as diferentes atividades de um mesmo pavimento.

Planilha 3 (cor laranja) - Circulação Vertical: compreendem o conjunto de escadas, elevadores, rampas, patamares, passarelas e seus componentes que interligam circulações horizontais e/ou atividades entre diferentes pavimentos.

Planilha 4 (cor amarela) - Salas: Compreende o conjunto de ambientes para uso público e semi-público que abrigam diferentes atividades, tais como, salas de aula e de reuniões, laboratórios e gabinetes.

Planilha 5 (cor verde) - Sanitário: compreende o conjunto de áreas e equipamentos para higiene pessoal, destinados a funcionários e usuários.

\subsection{Imersão (Vivência) Como Técnica de Complementação da Coleta de Dados}

Esta etapa teve como objetivo os pesquisadores passarem pela experiência análoga da mobilidade reduzida e/ou da pessoa com deficiência, tornando-os mais atentos para os problemas ainda não identificados ou, até mesmo, ratificando aqueles encontrados na primeira fase de coleta de dados (figura 8).
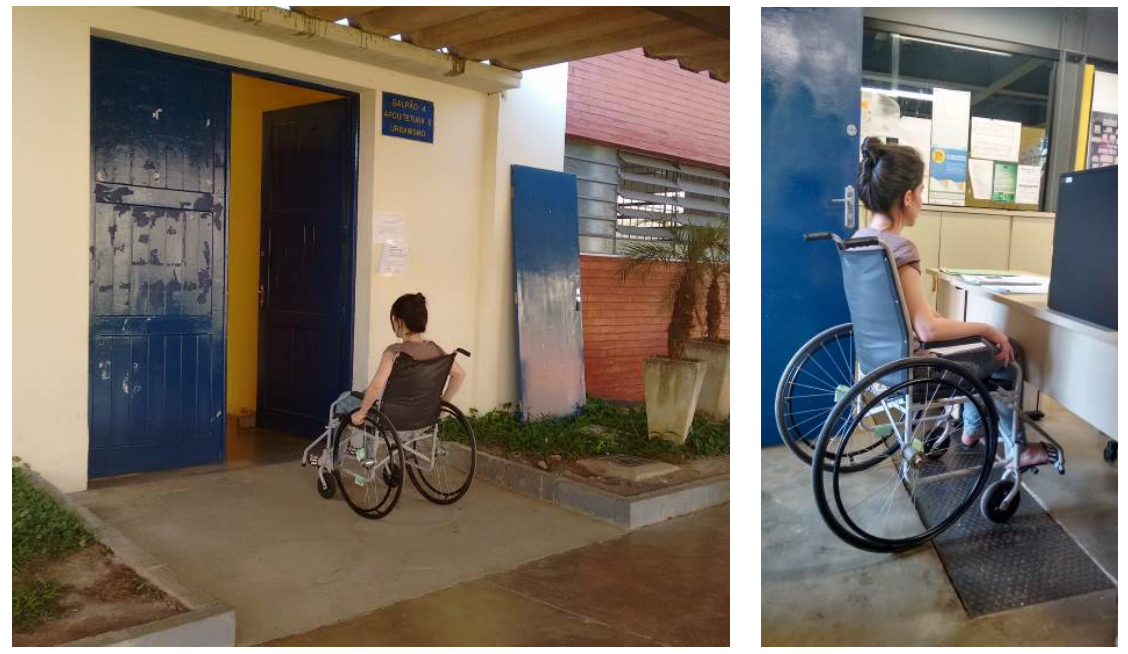

Figura 8 - Registros da coleta de dados durante a vivência dos pesquisadores. Fonte: Dos autores, 2014.

Destaca-se que, na vivência, priorizou-se o uso de uma cadeira de rodas. A cadeira utilizada foi da marca Ortometal e modelo 132 Pop - dobrável, com rodas maciças. Os pesquisadores foram divididos de forma que uma pessoa estivesse sentada na cadeira e uma segunda, à disposição para empurrá-la quando necessário. Os registros fotográficos e verbais ficaram a cargo de uma terceira pessoa que acompanhava o percurso. 


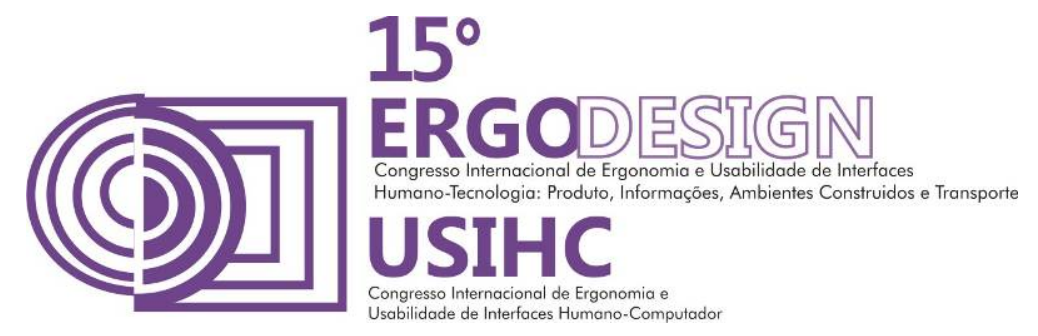

Ao final, os dados coletados na vivência foram incorporados aos dados já coletados nas observações realizadas anteriormente.

\section{PLANILHAS DE PROBLEMAS E SOLUÇÕES: SISTEMATIZAÇÃO DOS DADOS E PROPOSIÇÃO DE MELHORIAS}

A sistematização dos dados coletados e analisados estão apresentados neste artigo de acordo com o ambiente avaliado em cada uma das cinco planilhas aplicadas, identificando-se: (a) os principais problemas levantados; (b) a situação de acessibilidade; e (c) a solução proposta. Cada um dos itens mencionados está ordenado de acordo com o componente de acessibilidade espacial a que está relacionado: orientabilidade, comunicação, deslocamento e uso.

Conforme se pode constatar, nos setores analisados na Tabela 1, a implantação de tecnologias assistivas e a utilização de mobiliário acessível tornaria o ambiente adequado para receber um público mais diversificado. Destacam-se, principalmente, as barreiras criadas pela falta de orientabilidade, uma vez que há completa ausência de soluções de comunicação visual e espacial, e pela falta de mobiliário adequado.

Tabela 1 - Saguão, Recepção, administração. Fonte: dos autores, 2014.

\begin{tabular}{|c|c|c|c|c|}
\hline \multicolumn{5}{|c|}{ Saguão, recepção, administração } \\
\hline & 6 Orientabilidade & Comunicação & Deslocamento & Uso \\
\hline Problemas levantados & $\begin{array}{l}\text { Ausência de informação visual } \\
\text { e suporte tátil indicando a } \\
\text { função do edifício, rotas para } \\
\text { uso do mesmo, locais de } \\
\text { atendimento, bem como seus } \\
\text { mobiliários. }\end{array}$ & $\begin{array}{l}\text { Ausência de intérpretes e de } \\
\text { tecnologia assistiva que } \\
\text { permita a comunicação entre a } \\
\text { pessoa com restrição na fala } \\
\text { e/ou na audição com os } \\
\text { funcionários. }\end{array}$ & - & $\begin{array}{l}\text { Balcões de atendimento não } \\
\text { permite aproximação frontal por } \\
\text { cadeiras de roda. Não há } \\
\text { mobiliário de espera. } \\
\text { Bebedouro não acessivel (não } \\
\text { permite aproximação frontal, } \\
\text { bica com 1,05m, não há altura } \\
\text { livre). } \\
\end{array}$ \\
\hline Situação de Acessibilidade & $\begin{array}{l}\text { Dificuldade de acesso e } \\
\text { circulação de pessoas com } \\
\text { deficiência visual. }\end{array}$ & $\begin{array}{c}\text { Dificuldade de comunicação } \\
\text { entre funcionários e pessoas } \\
\text { com restrição na fala e/ou na } \\
\text { audição. } \\
\end{array}$ & - & $\begin{array}{c}\text { Balcão e bebedouros } \\
\text { inadequados, dificultando a } \\
\text { aproximação. }\end{array}$ \\
\hline Solução Proposta & $\begin{array}{l}\text { Criação do percurso com piso } \\
\text { tátil direcional e piso tátil de } \\
\text { alerta, além de mapas táteis, } \\
\text { no hall do prédio. }\end{array}$ & $\begin{array}{l}\text { Admissão de intérprete e/ou } \\
\text { aquisição se tecnologia } \\
\text { assitiva. }\end{array}$ & - & $\begin{array}{l}\text { Balcão com profundidade } \\
\text { recomendável segundo a } \\
\text { NBR9050 } 0,30 \mathrm{~cm} \text {. } \\
\text { Bebedouro com bica de } 90 \mathrm{~cm} \\
\text { de altura, altura livre inferior de } \\
\text { no minimo } 73 \mathrm{~cm} \text {, área de } \\
\text { aproximação frontal de } \\
0,80 \mathrm{~cm} \times 1,20 \mathrm{~m} .\end{array}$ \\
\hline
\end{tabular}




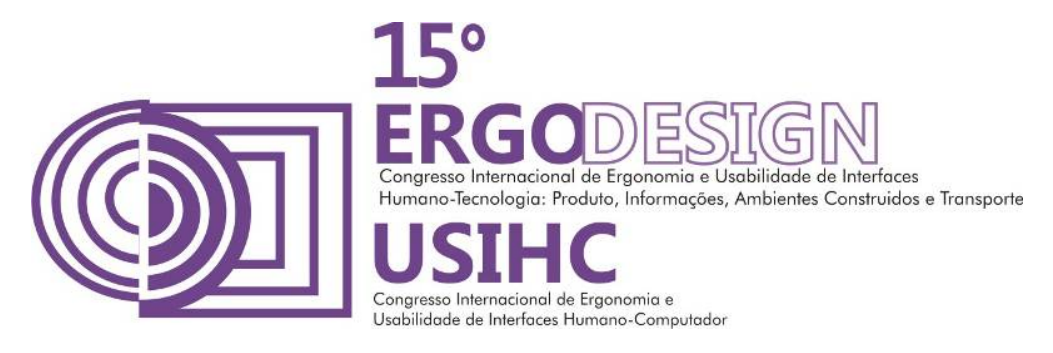

Tabela 2 - Circulações horizontais. Fonte: dos autores, 2014.

\begin{tabular}{|c|c|c|c|c|}
\hline \multicolumn{5}{|c|}{ Circulações horizontais } \\
\hline & Orientabilidade & Comunicação & Deslocamento & Uso \\
\hline Problemas levantados & $\begin{array}{c}\text { Ausência de indicação sonora } \\
\text { e visual em saídas de } \\
\text { emergência. } \\
\text { Ausência de sinalização de } \\
\text { rotas e entradas acessíveis, } \\
\text { bem como de sinalização visual } \\
\text { e visual em forma de } \\
\text { pictogramas }\end{array}$ & $\begin{array}{l}\text { Ausência de sistema de alarme } \\
\text { de incêndio simultaneamente } \\
\text { sonoro e luminoso. }\end{array}$ & $\begin{array}{l}\text { Inexistência de percurso com } \\
\text { piso tátil (textura e cor } \\
\text { diferenciada). } \\
\text { Material do piso não é } \\
\text { antiderrapante e estável } \\
\text { (cimento queimado). }\end{array}$ & - \\
\hline Situação de Acessibilidade & $\begin{array}{c}\text { Dificuldade em localizar rotas e } \\
\text { entradas acessiveis, bem como } \\
\text { os locais de acesso a pessoas } \\
\text { com deficiência. }\end{array}$ & - & $\begin{array}{l}\text { Piso escorregadio e propenso a } \\
\text { queda. }\end{array}$ & - \\
\hline Solução Proposta & $\begin{array}{c}\text { Em saídas de emergência } \\
\text { devem ser instalados alarmes } \\
\text { sonoros e visuais. Deve ser } \\
\text { prevista a sinalização } \\
\text { informativa, indicativa e } \\
\text { direcional da localização das } \\
\text { entradas acessíveis de acordo } \\
\text { com a seção } 5 \text { da NBR } 9050 \text {. }\end{array}$ & $\begin{array}{l}\text { Instalação de sinalização } \\
\text { utilizada para indicar a rotas de } \\
\text { fuga e saídas de emergência } \\
\text { da edificação, ou para alertar } \\
\text { quanto a um perigo iminente. }\end{array}$ & $\begin{array}{l}\text { Instalação de piso tátil. } \\
\text { Instalação de pisos com } \\
\text { superfície regular, firme, } \\
\text { estável e antiderrapante sob } \\
\text { qualquer condição, que não } \\
\text { provoque trepidação em } \\
\text { dispositivos com rodas. }\end{array}$ & - \\
\hline
\end{tabular}

Já nas circulações horizontais (Tabela 2), a substituição do piso por outro não escorregadio e a implantação de piso tátil são imprescindíveis para a segurança e o fácil acesso ao interior da edificação. Também neste setor, identificam-se os problemas de orientabilidade e comunicação, haja vista a inexistência de elementos de comunicação visual no edifício como um todo.

Tabela 3 - Circulações verticais. Fonte: dos autores, 2014. 


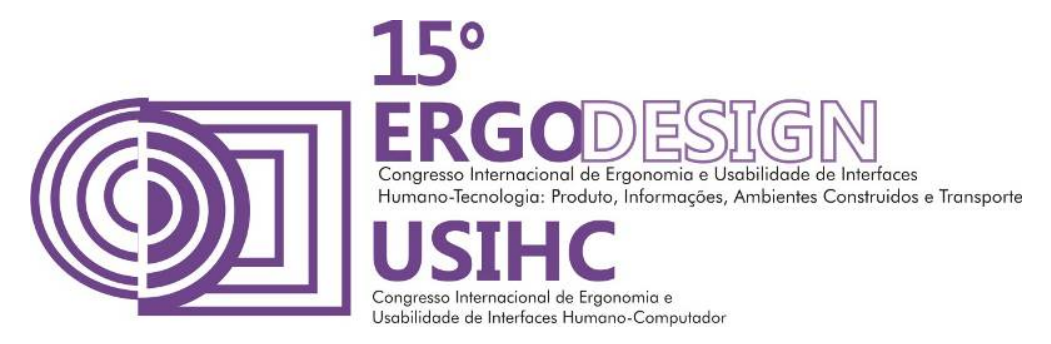

\begin{tabular}{|c|c|c|c|c|}
\hline \multicolumn{5}{|c|}{ Circulações Verticais } \\
\hline & Orientabilidade & Comunicação & Deslocamento & Uso \\
\hline Problemas levantados & $\begin{array}{c}\text { Ausência de sinalização tátil de } \\
\text { alerta no inicio e no término da } \\
\text { escada e da rampa, bem como } \\
\text { de sistema de iluminação de } \\
\text { emergência e de sistema de } \\
\text { sinalização para abandono do } \\
\text { local. }\end{array}$ & - & $\begin{array}{c}\text { Ausência de equipamento } \\
\text { eletromecânico de circulação } \\
\text { vertical. Escada em forma } \\
\text { curva, com piso escorregadio. }\end{array}$ & $\begin{array}{l}\text { Corrimãos somente em um } \\
\text { lado da escada. Corrimãos da } \\
\text { escada e da rampa sem } \\
\text { prolongamento mínimo e sem } \\
\text { extremidades recurvadas antes } \\
\text { do seu início. Altura } \\
\text { inadequada do guarda-corpo. }\end{array}$ \\
\hline Situação de Acessibilidade & & - & $\begin{array}{c}\text { Existe o local para implantação } \\
\text { de elevador ou plataforma, } \\
\text { entretanto há ausência de tal } \\
\text { equipamento. Escada com } \\
\text { piso escorregadio. }\end{array}$ & Risco de acidente \\
\hline Solução Proposta & $\begin{array}{c}\text { Instalar nos degrau sinalização } \\
\text { visual na borda do piso, em cor } \\
\text { contrastante com a do } \\
\text { acabamento, medindo entre } \\
0,02 \mathrm{~m} \text { e } 0,03 \mathrm{~m} \text { de largura. } \\
\text { Instalar sinalização tátil de } \\
\text { alerta, perpendicular ao } \\
\text { sentido de deslocamento, no } \\
\text { início e término da escada e } \\
\text { rampa, em cor contrastante } \\
\text { com a do piso, com largura } \\
\text { entre } 0,25 \mathrm{~m} \text { a } 0,60 \mathrm{~m}, \\
\text { afastada de } 0,32 \mathrm{~m} \text { no máximo } \\
\text { do ponto onde ocorre a } \\
\text { mudança do plano. Instalação } \\
\text { de iluminação de emergência } \\
\text { bem como sinalização para } \\
\text { abandono do local. }\end{array}$ & - & $\begin{array}{l}\text { Instalação de elevador ou } \\
\text { plataforma. } \\
\text { Instalação de piso } \\
\text { antiderrapante. }\end{array}$ & $\begin{array}{l}\text { Instalação de corrimão no lado } \\
\text { da escada que não possui. } \\
\text { Adequar os corrimãos laterais, } \\
\text { onde estes devem prolongar-se } \\
\text { pelo menos } 30 \mathrm{~cm} \text { antes do } \\
\text { início e após o término da } \\
\text { rampa e da escada. As } \\
\text { extremidades dos corrimãos } \\
\text { devem ter acabamento } \\
\text { recurvado, ser fixadas ou } \\
\text { justapostas à parede ou piso, } \\
\text { ou ainda ter desenho contínuo, } \\
\text { sem protuberâncias. } \\
\text { Adequar o guarda-corpo da } \\
\text { rampa e da escada a altura de } \\
1,05 \mathrm{~m} \text {. }\end{array}$ \\
\hline
\end{tabular}

O terceiro setor analisado foi o das circulações verticais (Tabela 3). Conforme mencionado anteriormente, para a circulação entre os dois pavimentos, o edifício conta como uma escada interna e uma rampa externa. Para a melhoria da qualidade de vida verifica-se a necessidade de instalação de um elevador, uma vez que já há um espaço destinado ao mesmo no edifício. Ainda, algumas medidas poderiam ampliar a segurança e acessibilidade: sinalização tátil, iluminação de emergência, placas indicativas de saídas, adequação dos corrimões e guardacorpos.

Já no âmbito das salas e laboratórios, cujas recomendações estão apresentadas na Tabela 4, as bancadas e mesas de trabalho são acessíveis, embora não seja reguláveis, o que dispensa investimentos com a substituição imediata. No entanto, os armários necessitam de adaptação para que, por exemplo, um cadeirante pudesse acessá-lo completamente.

Por fim, a partir da Tabela 5, verifica-se a necessidade de adequação dos sanitários para pessoa com deficiência segundo os padrões normatizados, além da construção desse tipo de sanitário no primeiro pavimento. Conforme se pode constatar, esse setor apresenta problemas em todos os campos de análise: orientabilidade, comunicação, deslocamento e uso. 


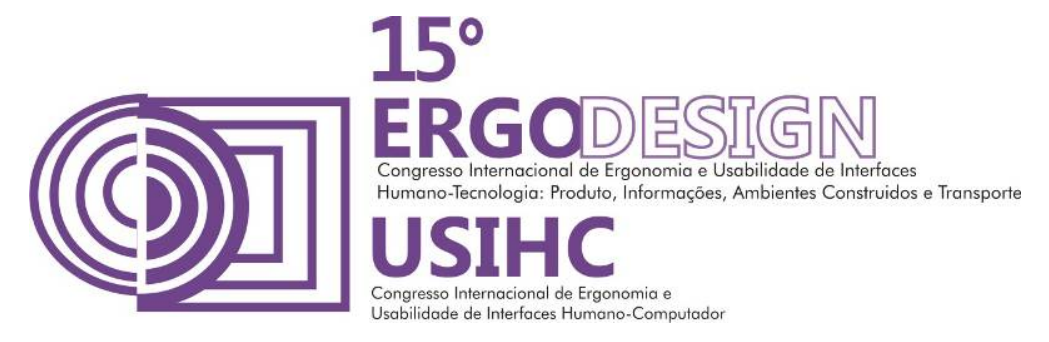

Quadro 4 - Salas e Laboratórios. Fonte: Dos autores, 2014.

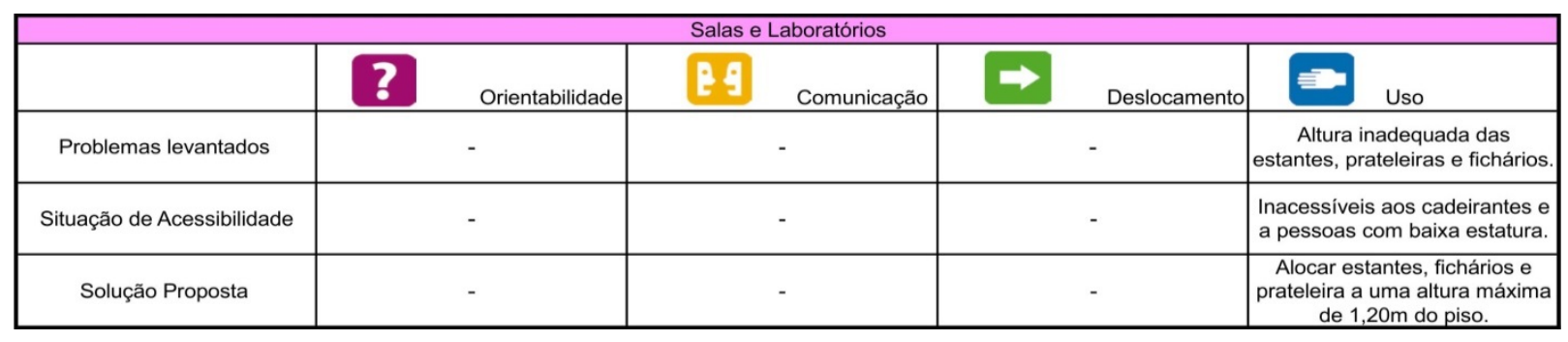

Quadro 5 - Sanitários. Fonte: dos autores, 2014.

\begin{tabular}{|c|c|c|c|c|}
\hline \multicolumn{5}{|c|}{ Sanitários } \\
\hline & 2 Orientabilidade & $3:$ & Deslocamento & ב- \\
\hline Problemas levantados & $\begin{array}{c}\text { Não há sinalização } \\
\text { identificando a localização e o } \\
\text { tipo de sanitário. }\end{array}$ & $\begin{array}{l}\text { Não há sinalização de } \\
\text { emergência ao lado da bacia. }\end{array}$ & $\begin{array}{c}\text { Há apenas um sanitário para } \\
\text { pessoas com deficiência, } \\
\text { sendo que, este encontra-se no } \\
2^{\circ} \text { pavimento. A porta do } \\
\text { sanitário abre para dentro e } \\
\text { devido à presença de estoque } \\
\text { de materiais atrás da mesma, } \\
\text { ela não pode ser totalmente } \\
\text { aberta. }\end{array}$ & $\begin{array}{c}\text { Área livre com dimensões } \\
\text { inadequadas. Barra de apoio } \\
\text { afixada de forma inadequada. } \\
\text { Lavatório sem altura livre e com } \\
\text { coluna. } \\
\text { Torneiras inadequadas. }\end{array}$ \\
\hline Situação de Acessibilidade & $\begin{array}{l}\text { Dificuldade em localizar os } \\
\text { sanitários. }\end{array}$ & $\begin{array}{l}\text { Dificuldade de obter ajuda em } \\
\text { caso de queda. }\end{array}$ & $\begin{array}{c}\text { Grande esforço para a pessoas } \\
\text { com deficiência que esta no } 1^{\circ} \\
\text { pavimento chegar ao sanitário. } \\
\text { Dificuldade para o cadeirante } \\
\text { entrar no sanitário, pois a porta } \\
\text { não abre por completo devido a } \\
\text { materiais de limpeza atrás } \\
\text { desta. }\end{array}$ & $\begin{array}{l}\text { Dificuldade de uso do sanitário } \\
\text { por pessoas com deficiência. }\end{array}$ \\
\hline Solução Proposta & $\begin{array}{l}\text { Colocar sinalização em cores } \\
\text { contrastantes e acessivel a } \\
\text { pessoas com restrição visual } \\
\text { identificando a localização e o } \\
\text { tipo do sanitário. }\end{array}$ & $\begin{array}{c}\text { Colocar sinalização de } \\
\text { emergência ao lado da bacia a } \\
\text { uma altura de } 40 \mathrm{~cm} \text {. }\end{array}$ & $\begin{array}{c}\text { Construção de um sanitário } \\
\text { para pessoa com deficiência no } \\
1^{\circ} \text { pavimento e retirada do } \\
\text { material de limpeza de trás da } \\
\text { porta bem como a adequação } \\
\text { desta. }\end{array}$ & $\begin{array}{c}\text { Criar uma área livre de } 80 \times 120 \\
\mathrm{~cm} \text { ao lado do vaso sanitário. } \\
\text { Fixar barras de apoio com no } \\
\text { mínimo } 80 \mathrm{~cm} \text { de comprimento } \\
\text { e a uma distancia de } 75 \mathrm{~cm} \text { do } \\
\text { piso nas laterais e no fundo da } \\
\text { bacia sanitária. Substituir o } \\
\text { lavatório existente por um } \\
\text { suspenso (sem coluna) fixado a } \\
\text { uma altura entre } 78 \mathrm{~cm} \text { e } 80 \mathrm{~cm} \\
\text { do piso e com uma altura livre } \\
\text { sob o lavatório de } 73 \mathrm{~cm} \text {. } \\
\text { Colocar torneira do tipo } \\
\text { alavanca. }\end{array}$ \\
\hline
\end{tabular}

Logo, ao se analisar todos os quadros de melhorias supracitados em forma de tabelas, pode-se constatar que a maioria das soluções propostas não exigem elevadas montas de recurso financeiro, sobretudo se comparadas com os benefícios que poderão repercutir na qualidade de vida dos usuários do local. As obras consideradas com maior custo financeiro são a instalação do elevador (ou plataforma para cadeirante) e a construção de um segundo sanitário para deficientes no andar térreo. 


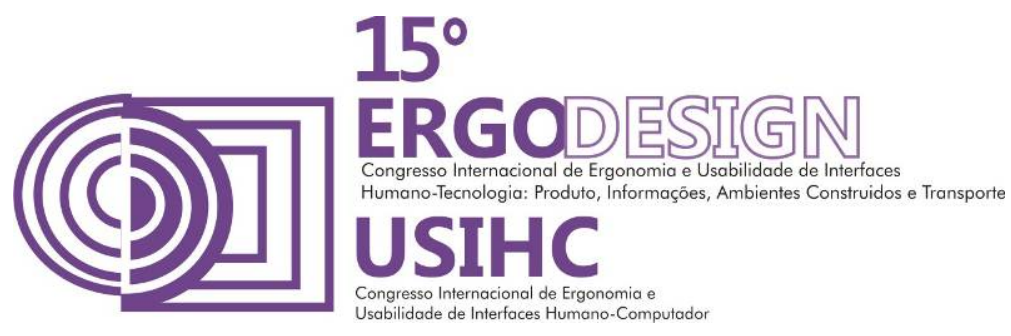

\section{CONSIDERAÇÕES FINAIS}

Embora o tema da acessibilidade em edifícios públicos venha sendo debatido em várias esferas do conhecimento e da prática profissional, ainda se observam lacunas importantes no que tange à adequação dos ambientes às normas de acessibilidade, para as quais arquitetos, designers e ergonomistas podem contribuir. É nesse sentido que a pesquisa aqui relatada buscou dar a sua contribuição, compondo um quadro de melhorias para o edifício que está submetido a um projeto de reforma de interiores.

Vislumbra-se, como um desdobramento, a realização uma sensibilização com a equipe responsável pelo projeto de reforma. Busca-se, também, o acompanhamento do desenvolvimento do projeto, verificando-se quais foram as sugestões aceitas e quais foram rejeitadas, identificando-se os motivos da rejeição e as soluções arquitetônicas adotadas para as recomendações aceitas.

\section{REFERÊNCIAS BILBIOGRÁFICAS}

ASSOCIAÇÃO BRASILEIRA DE NORMAS TÉCNICAS. NBR 9050: Acessibilidade de pessoas portadoras de deficiências a edificações, espaço, mobiliário e equipamentos urbanos. Rio de Janeiro, 2004.

CORRÊA, R. M. (org.). Avanços e desafios na construção de uma sociedade inclusiva. Belo Horizonte : Sociedade Inclusiva/PUC-MG, 2008.

DUARTE, C. R.; COHEN, R. Research and Teaching of Accessibility and Universal Design in Brazil: hindrances and challenges in a developing country. Anais Universal Design and Visitability: From Accessibility to Zoning Conference. 13-14 July, 2006, Ohio State University.Goldsmith, 2004.

DISCHINGER, M; ELY, V. H; PIARDI, S. M. Promovendo acessibilidade espacial nos edifícios públicos: Programa de Acessibilidade às Pessoas com Deficiência ou Mobilidade Reduzida nas Edificações de Uso Público. Florianópolis: MPSC, 2012.

MEIRA, A. R; ARAÚJO, N. M. C. Acessibilidade em edificações de uso público: uma análise à luz da avaliação pós-ocupação. In: COSTA, A. D. L, ARAÚJO, N. M. C. (Org.). Acessibilidade no Ambiente Construído: questões contemporâneas. João Pessoa, PB: IFPB, 2013. p.141-166.

MORAES, A. M. de; MONT'ALVÃO, C. Ergonomia: conceitos e aplicações. 3. ed. Rio de Janeiro: 2AB, 2007.

\section{AGRADECIMENTOS}

Os agradecimentos são direcionados à Pró-Reitoria de Pesquisa da UFJF, ao CNPq e à FAPEMIG (Fundação de Amparo a Pesquisa do Estado de Minas Gerais), pelo apoio ao desenvolvimento da pesquisa e apresentação deste trabalho. 